\title{
Unprotected Left Main is now no more Domain of Surgeon
}

\author{
Ranjit Sharma*, Anish Hirachan, Milan Gautam, Prabesh Neupane \\ Department of Cardiology, Nepal Mediciti Hospital, Lalitpur, Nepal
}

*Corresponding Author: Ranjit Kumar Sharma, Department of Cardiology, Nepal Mediciti, Lalitpur 44600 Nepal

Received Date: August 03, 2021; Accepted Date: August 16, 2021 ; Published Date: August 20,2021

Citation: Ranjit Sharma, Anish Hirachan, Milan Gautam, Prabesh Neupane (2021) Unprotected Left Main is now no more Domain of Surgeon. J. Clinical Cardiology and Cardiovascular Interventions, 4(14); Doi:10.31579/2641-0419/209

Copyright: ( 2021 Chaitali Sen Dasgupta, This is an open-access article distributed under the terms of the Creative Commons Attribution License, which permits unrestricted use, distribution, and reproduction in any medium, provided the original author and source are credited.

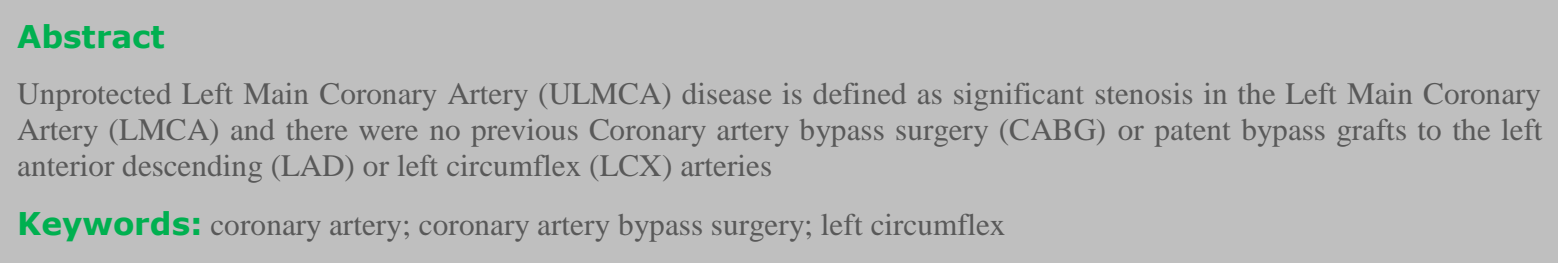

\section{Introduction:}

Unprotected Left Main Coronary Artery (ULMCA) disease is defined as significant stenosis in the Left Main Coronary Artery (LMCA) and there were no previous Coronary artery bypass surgery $(\mathrm{CABG})$ or patent bypass grafts to the left anterior descending (LAD) or left circumflex (LCX) arteries [1]. It is associated with high mortality as it supplies a large area of the myocardium - approximately $84 \%$ of the left ventricle in the right dominant system and $100 \%$ in a left dominant system [2]. ULMCA disease constitutes 5 to $7 \%$ of the patients undergoing coronary angiography [3]. The LMCA disease (i.e., > 50\% stenosis) was found in $1477(7.3 \%)$ of 20137 patients in the Coronary Artery Surgery Study (CASS) registry [4]. Significant LMCA stenosis is defined as a $>50 \%$ diameter stenosis, and the left main equivalent disease is defined as severe $(70 \%)$ diameter stenosis of the proximal LAD and proximal left circumflex as judged by contrast angiography [5].

The left main coronary artery (LMCA) usually arises from the left coronary sinus, It passes between the pulmonary trunk and the left atrial appendage and just under the appendage in $70 \%$ of individuals bifurcates into the left anterior descending artery and left circumflex artery, and 30\% trifurcates into an additional ramus intermedius [6]. An anomalous takeoff from or above the right sinus of Valsalva represents a relatively common anatomic variant. Notably, the rare (estimated prevalence $0.03 \%$ ) LM with an anomalous origin from the right coronary sinus and "intra-arterial" course between the aorta and pulmonary artery is associated with the risk of sudden death [7].

The LMCA contains a higher elastic tissue component compared to the rest of the coronary tree which can explain elastic recoil and high restenosis rate following balloon angioplasty. The ostium of the LMCA lacks the tunica adventitia and is richer in smooth muscle cells and elastic tissue than any other portion of the LMCA and its branches [8]. The LM is a large diameter artery with important variability across different individuals. The mean "reference" diameter, derived from a large intravascular ultrasound (IVUS) study is $5 \mathrm{~mm}$ and ranges between 3.5 and $6.5 \mathrm{~mm}$ with a mean length of $10.5 \pm 5.3 \mathrm{~mm}$ [9]. Usually, the short ostium is associated with the bicuspid aortic valve [10]. When considering the side branch relevance according to the amount of myocardium supplied, the left main bifurcation is known to have its major side branch (i.e., the LCX) supplying $>10 \%$ of the myocardial mass in more than $95 \%$ of cases [11].

The left main disease most commonly occurs due to atherosclerosis, whereas other less common causes include vasospasm, arteritis, radiation, extrinsic compression [12]. LM disease is categorized into "ostial", "midshaft" or "distal" based on angiography [13]. The distribution of LMCA lesions is approximately $10 \%$ ostial, predominantly occurring in young women, about $70 \%$ in the distal left main artery, and the remainder $20 \%$ in the shaft. In $>80 \%$ of the cases, it is associated with multivessel involvement [14].

In up to $40 \%$ of patients, LM disease is associated with significant carotid artery stenosis [15]. In a study by Oviedo, it was found that continuous plaque from the LMCA into

the proximal LAD artery was seen in $90 \%$, from the LMCA into the LCX artery in $66.4 \%$, and from the LMCA into both the LAD and LCX arteries in $62 \%$. Plaque localized to either LAD or LCX ostium and not involving distal LMCA was seen in only $9.3 \%$ of LAD arteries and $17.1 \%$ of LCX arteries [16]. When the LM bifurcation is diseased, intimal atherosclerosis is accelerated primarily in the area of low shear stress in the lateral wall close to the LAD and Lacs bifurcation and the carena is frequently free of disease [17]. 


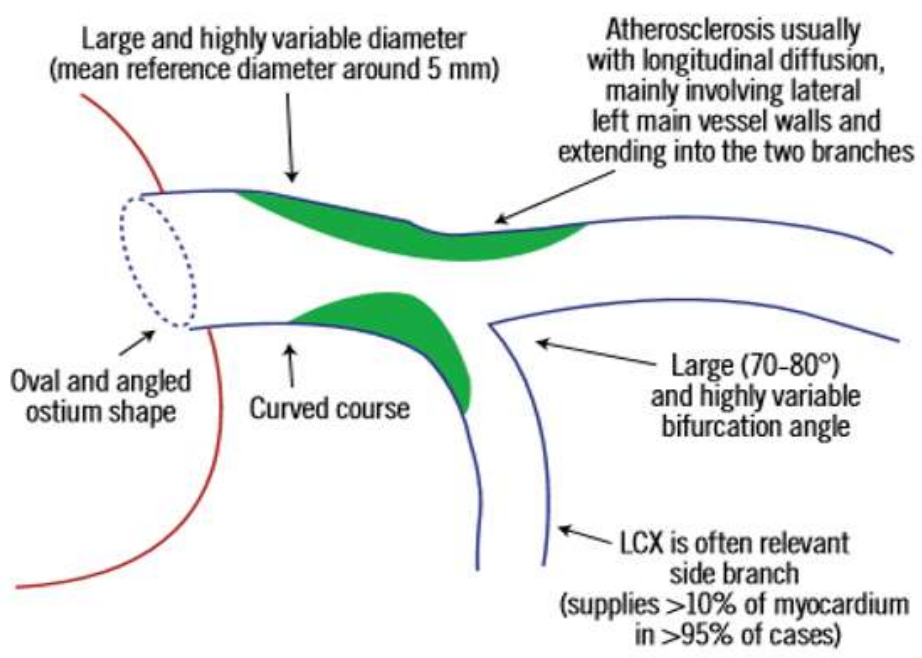

Figure 1: Schematic representation of left main anatomical features.

Coronary artery bypass surgery $(\mathrm{CABG})$ has been the standard management for patients with ULMCA disease [18]. In the review of the Cleveland Clinic experience of CABG for patients with LM stenosis, Sabik et al report a 20-year follow-up of all patients operated on between 1971 and 1998. They have shown that for the 3803 patients with LM stenosis, 30-day survival is $97.6 \%$, with $93.6 \%$ at 1 year and $83 \%$ at 5 years. The ten-year survival rate is $64 \%$. Importantly, rates of freedom from coronary reintervention are $99.7 \%$ at 30 days, $98.9 \%$ at 1 year, and $89 \%$ at 5 years. At 10 years, $76 \%$ of surviving patients remain free from reintervention and $61 \%$ at 20 years [19].

Percutaneous treatment of LMCA stenosis was made by Andreas Gruentzig in 1977 [20]. The first series of 129 patients, reported by Hartzler and O'Keefe in 1989, showed a $10 \%$ in-hospital mortality and $64 \%$ 3-year mortality, the practice was quickly abandoned due to poor outcomes and better surgical results [21]. However, subsequent advancements in percutaneous coronary interventional tools, techniques, and pharmacotherapy have made it a sustainable alternative to CABG. Moreover, several observational, non-randomized registries have shown no difference in the occurrence of MACCE between patients treated with DES compared with the ones treated with $\mathrm{CABG}$ in this subset of patients up to 5 years of clinical follow-up and these trials also demonstrated how much PCI has been improved for LMCA treatment.

Current guidelines recommend revascularization for $>50 \% \mathrm{LM}$ stenosis [22]. However, the recommendations for PCI vary depending upon the anatomical complexity (low, intermediate, and high) of the unprotected LMCAD and patient complexity. Although CABG is class I (level of evidence B), with a growing body of evidence for ULMCA intervention, PCI in those patients with SYNTAX score $\leq 22$ has equivalent indication class I (level of evidence B) as per current European practice guidelines. Patients with SYNTAX scores (22-32) have a class IIa (level of evidence B) indication whereas CABG is preferred in patients with a SYNTAX score $\geq$ of 32. AHA/ACC/SCAI (American Heart Association/ American College of Cardiology/Society of Cardiovascular Angiography and Interventions) guidelines assigned class IIa recommendation in patients with favorable anatomy (SYNTAX $<22$ and ostial or trunk LM disease) and in patients with clinical characteristics that predict an increased risk of adverse surgical outcomes (e.g., moderate-severe chronic obstructive pulmonary disease, disability from the previous stroke, or previous cardiac surgery; STS-predicted risk of operative mortality $>2 \%$ [23].

Trial Evidence for LM Stenting

\begin{tabular}{|c|c|c|c|c|c|c|}
\hline \multirow[b]{2}{*}{ RCT } & \multirow[b]{2}{*}{ Year } & \multicolumn{2}{|c|}{ Patients (N) } & \multirow[b]{2}{*}{ Follow Up (Years) } & \multirow[b]{2}{*}{ Stents Used } & \multirow[b]{2}{*}{ Main Outcome } \\
\hline & & $\mathrm{PCl}$ & CABG & & & \\
\hline LEMANS $^{20}$ & 2008 & 52 & 53 & 2 & BMS, DES (35\%) & $\begin{array}{l}\mathrm{PCl} \text { group had improved } \\
\text { ejection fraction }\end{array}$ \\
\hline SYNTAX-LM ${ }^{21}$ & 2010 & 357 & 348 & I & PES & $\begin{array}{c}\text { MACCE } 13.7 \% \text {, similar to } \\
\text { CABG patients }\end{array}$ \\
\hline Boudriot et $a^{12} 2$ & 2011 & 100 & 101 & 1 & SES & $\begin{array}{c}\text { MACCE } 19 \% \text {, non-inferior } \\
\text { to CABG }\end{array}$ \\
\hline PRECOMBA $^{\mathrm{T} 2} 3$ & 2011 & 300 & 300 & 2 & SES & $\begin{array}{c}\text { MACCE } 8.7 \% \text {, non-inferior } \\
\text { to CABG }\end{array}$ \\
\hline $\mathrm{EXCE}^{12} 4$ & 2016 & 948 & 957 & 3 & EES & $\begin{array}{l}\text { Primary outcome } 15.4 \% \text { in } \\
\qquad \mathrm{PCl} \text { arm }\end{array}$ \\
\hline $\mathrm{NOBL}^{\mathrm{E} 25}$ & 2016 & 598 & 603 & 5 & SES, BES & MACCE $28 \%$ for $\mathrm{PCl}$ \\
\hline
\end{tabular}

Table 1: Randomized Controlled Trials of LMCA Intervention Comparing With CABG

The SYNTAX trial included a subset of 705 patients with LM disease. There was no significant difference in MACCE (death, MI, stroke, and repeat revascularization) at 5 years $(36.9 \%$ in PCI patients and $31 \%$ in CABG patients) (HR 1.23; 95\% CI: 0.95-1.59; $\mathrm{p}=0.12$ ). 


\begin{tabular}{|c|c|c|c|c|c|}
\hline Regsistry & rear & $\begin{array}{l}\text { LMPCi } \\
\text { patients (N) }\end{array}$ & $\begin{array}{l}\text { Follow up } \\
\text { crears? }\end{array}$ & Stents Used & Main Outcome \\
\hline MAIN-Compare" & 2008 & 1102 & 2.7 & $\begin{array}{c}\text { BMS }(28.996): \\
\text { DES SES and PES } \\
(71.196)\end{array}$ & $\begin{array}{l}\text { Deach and composite } \\
\text { outcome similar. TVR } \\
\text { higher in the PCI gnoup }\end{array}$ \\
\hline DELFT'2 & 2009 & 358 & 3 & SES and PES & $\begin{array}{l}\text { MACE at } 30 \text { days } \\
11.4 \% \text {, at } 3 \text { year } 32.1 \% 6\end{array}$ \\
\hline FRIEND'S & 2009 & 151 & 1.2 & PES & $\begin{array}{l}\text { MACE } 10.696 \\
\text { B.195 mortality in the }\end{array}$ \\
\hline CUSTOMIZE'. & 2011 & 342 & 2 & DES & $\begin{array}{c}\text { SrNTAX scone } 34: \\
32.796 \text { in the srNTAX } \\
\text { score }>34\end{array}$ \\
\hline CREDO-KYOTO'S & 2012 & 365 & 3 & DES (68.396) & $\begin{array}{l}\text { Adjusted death/ } \\
\text { M1/stroke simitar } \\
\text { to CABG. Fepeat } \\
\text { revascularization } 43.4 \%\end{array}$ \\
\hline DELTAN & 2012 & 1874 & 3.5 & $\begin{array}{l}\text { SES }(4.4 .796) \text { and } \\
\text { PES }(47.696)\end{array}$ & $\begin{array}{r}\text { MACCE } 34.996 \text { and TVR } \\
15.596\end{array}$ \\
\hline IRIS-MAIN 3" & 2016 & 2866 & 9.7 .5 . 6 , and 3 & $\begin{array}{c}\text { BMS, nrst-and } \\
\text { second-generation } \\
\text { DES }\end{array}$ & $\begin{array}{l}\text { Rate of repeat } \\
\text { revascularization } \\
\text { decreased over time }\end{array}$ \\
\hline $\begin{array}{l}\text { MILAN-NEW TOKYO } \\
\text { (MITO REgISEY' }\end{array}$ & 2016 & 1026 & 4.3 & DES & $\begin{array}{c}\text { MACE } 31.896 . \text { TLR } \\
19.296\end{array}$ \\
\hline ZMENG" & 2016 & 1412 & 3 & DES & $\begin{array}{l}\text { Alt-cause mortality } \\
3.896, T V R \text { 9.996 }\end{array}$ \\
\hline
\end{tabular}

Table 2: Registries of LM Intervention

Mortality was 12.8 and $14.6 \%$ in PCI and CABG patients, respectively (HR 0.88 [0.58, 1.32]; $\mathrm{p}=0.53$ ). Stroke was significantly increased in the CABG group and repeat revascularization in the PCI arm. MACCE was similar between arms in patients with low/intermediate SYNTAX scores but significantly increased in PCI patients with high scores $(\geq 33)$ [24].

In the EXCEL (Evaluation of XIENCE versus Coronary Artery Bypass Surgery for Effectiveness of Left Main Revascularization) trial, 1,905 patients - with ULMCA disease with $\geq 70 \%$ diameter

stenosis, or $\geq 50 \%$ or $\leq 70 \%$ with either (1) noninvasive evidence of LM ischemia, (2) intravascular ultrasound-derived minimal lumen area $($ IVUS-MLA) $\leq 6.0 \mathrm{~mm} 2$, or (3) fractional flow reserve $(\mathrm{FFR}) \leq 0.80$, SYNTAX score $\leq 32$, and clinical and anatomic eligibility for both PCI and CABG as agreed to by the local heart team - were randomized to PCI with fluoropolymer-based cobalt-chromium everolimus-eluting stents or
CABG. The primary endpoint, the composite of death from any cause, stroke, or MI at 3 years occurred in $15.4 \%$ of patients who underwent PCI group versus $14.7 \%$ of the patients who underwent $\mathrm{CABG}$ group meeting the noninferiority criterion. The secondary endpoint event of death, stroke, or MI at 30 days was lower in the PCI group (4.9\% in the PCI group vs. $7.9 \%$ in the CABG group). The secondary endpoint event of death, stroke, MI, or ischemia-driven revascularization at 3 years occurred in fewer patients in the PCI group. CABG patients had fewer primary endpoint events than the PCI group patients between 30 days and 3 years after the procedure. Revascularization rates at 3

Years were higher with PCI than with CABG (12.6 vs. $7.5 \%$ ) whereas the rates of early MI and major adverse events were lower with PCI than with CABG (8.1 vs. $23.0 \%)$ [25].

\begin{tabular}{|c|c|c|c|c|}
\hline & SYNTAX & PRECOMBAT & NOBLE 12 & EXCEL: \\
\hline Publication year & 2014 & 2015 & 2020 & 2019 \\
\hline Number of patients & 705 & 600 & 1,201 & 1,905 \\
\hline \multirow[t]{2}{*}{ Length of follow-up } & 5 years & 5 years & 5 years & 5 years \\
\hline & MACCE & MACCE & MACCE & Composite death, stroke or MI \\
\hline \multicolumn{5}{|c|}{ Primary outcome (PCI versus CABG) } \\
\hline & 36.9 versus $31 \%,(p=0.12)$ & 17.5 versus $14.3 \%(p=0.26)$ & 28 versus $19 \%(\mathrm{p}=0.0002)$ & 22 versus $19.2 \%(\mathrm{p}=0.13)$ \\
\hline \multicolumn{5}{|c|}{ Secondary Outcomes (PCI vorsus CABG) } \\
\hline All-cause mortality & 12.8 versus $14.6 \%(p-0.53)$ & 5.7 versus $7.9 \%(\mathrm{p}-0.32)$ & 9 versus $9 x_{0}(p-0.68)$ & 13 versus $9.9 \%$ \\
\hline MI & 8.2 versus $4.8 \%(\mathrm{pm} 0.1)$ & 2 versus $1.7 \%(\mathrm{D}=0.76)$ & 8 versus $3 \%(p=0,0002)$ & 10.6 versus 9.19 \\
\hline stroke & 1,5 versus $4,3 \%(p-0.03)$ & 0.7 versus $0.7 \%(\mathrm{p}-0.99)$ & 4 versus $2 \times(p-0.11)$ & 2.9 versus $3.7 \%$ \\
\hline Repeat revascularisation & 26.7 versus $15.5 \%$ (p<-0.001) & 13 versus $7.396(p-0.020)$ & 17 versus $10 \%(\mathrm{p}=0.0009)$ & 17.2 versus $10.5 \%$ \\
\hline
\end{tabular}

Table 3: Randomized Controlled Trials Included in the Analysis

The EXCEL trial enrolled predominantly males (76\%). Most patients were clinically at low risk $(60 \%$ had stable ischemic heart disease and most patients had normal ejection fraction). Thirty percent were diabetic. According to the sites, the SYNTAX was low $(\leq 22)$ in $60.5 \%$ of the patients and intermediate (23-32) in $39.5 \%$ of the patients. The core laboratory assigned higher scores, low in $35.8 \%$ of the patients, intermediate in $40.0 \%$, and high $(\geq 33)$ in $24.2 \%$, the group that met the exclusion criteria. Most of the patients $(80.5 \%)$ had distal left main bifurcation or trifurcation disease, and two- or three-vessel coronary artery disease was present in $51.3 \%$ of the patients. Average 1.9 lesions were treated per patient. A mean of 2.4 stents with a mean total stent length of $49.1 \mathrm{~mm}$ was implanted per patient. Femoral access was used in $73 \%$ of patients, and IVUS guidance was used in $77 \%$ of patients. Offpump CABG was performed in $29 \%$. Internal mammary artery (IMA) was used in $98.8 \%$ with bilateral IMA in $28.8 \%$ of patients.

NOBLE (Nordic-Baltic-British Left Main Revascularization Study) trial11 randomized patients with significant LM lesion visually assessed stenosis diameter $\geq 50 \%$ or FFR $\leq 0.80$ and no more than three additional non-complex lesions (additional non-LM complex lesions were chronic total occlusions, bifurcation lesions requiring two-stent strategies, calcified or tortuous lesions). A total of 1,201 patients were randomly assigned to PCI or CABG. Kaplan-Meier 5-year estimates of MACCE (death from any cause, nonprocedural MI, repeat revascularization, or stroke) were $29 \%$ for PCI and 19\% for CABG (HR 1.48; 95\% CI: 1.11 1.96) with CABG being significantly better than PCI. Though all-cause mortality was not different, the rates of MI, revascularization and stroke were higher in PCI patients compared with CABG patients. Repeat revascularization was higher due to de novo lesion and target non-LMCA lesion revascularization. Notably, 1-year MACCE was the same in both groups. Surprisingly there was no association between the SYNTAX score and MACCE. Twenty percent of the population was female with $15 \%$ diabetics. Eighty percent had stable angina and most had preserved ejection fraction. Eighty-eight percent had distal LM lesions. Elective double stenting was used in $35 \%$ with culotte being the preferred technique. $11 \%$ of PCI cases received the first-generation DES in the LM. Kissing balloon inflation (KBI) was done in $55 \%$, and any ostial circumflex post-dilatation was done in $79 \%$. Complete revascularization was achieved in $92 \%$. IVUS was done pre-PCI in $47 \%$ and post-PCI in $74 \%$. CABG was done with the on-pump technique in $84 \%$, with $93 \%$ of patients receiving left internal mammary artery. The number of grafts per 
patient was one in $4 \%$, two in $52 \%$, three in $39 \%$, four in $4 \%$, and five in $<1 \%$ of patients [26].

At present, combined data from the above six trials of 2355 patients randomized to LM PCI and 2362 patients randomized to CABG suggest non-inferiority of PCI about survival. However, higher repeat revascularizations in the PCI group remain a concern when compared to CABG. It may be concluded that PCI works best for Ostial and shaft lesions and in patients with SYNTAX score < 33. In LM bifurcations and those with SYNTAX score > 33, CABG may be preferred although an individualized approach may be prudent [27].

\section{Conflicting Results of EXCEL and NOBLE}

1. Differences between studies in patient assessment, risk profiles, trial process, or procedural characteristics.

2. Differences in the stent used: EXCEL used a thin strut fluoropolymerbased cobalt-chromium everolimus-eluting stents whereas NOBLE used first-generation sirolimus-eluting Cypher stent $(11 \%)$ or the biolimuseluting Biomatrix Flex stent (89\%), resulting in a substantial difference in-stent thrombosis $(0.7$ vs. $3 \%)$. As a result, the rate of stent thrombosis or symptomatic graft occlusion was much higher after CABG than after PCI (5.4 vs. $0.7 \%$ ) in EXCEL but similar (4 vs. $3 \%$ ) in NOBLE.

3. Strategy of stenting: Both trials used a provisional stenting approach. In approximately $75 \%$ of patients, IVUS was used. Data were not available from EXCEL regarding the two-stent strategy. Thirty-five percent needed a two-stent strategy with the culotte technique being used in the majority in NOBLE.

4. Differences in primary endpoint used: EXCEL used death, MI, and stroke. Investigators included periprocedural MI. The EXCEL trial did not include repeat revascularization. The NOBLE trial, on the other hand, used only nonprocedural $\mathrm{MI}$ in the endpoint, and repeat revascularization was part of the primary composite endpoint. In the NOBLE trial, there was not much difference in target LM artery revascularization but more than a twofold increase in de novo lesion revascularization in the PCI group with most patients undergoing repeat PCI (96\%). 5. Difference in trial duration: EXCEL reported data at 3 years whereas NOBLE reported data at 5 years. Remarkably in NOBLE, the 5-year mortality was not different in PCI and CABG groups whereas death, stroke, and repeat revascularization was higher in the PCI group. Data from EXCEL may look similar to NOBLE if repeat revascularization is included with an evaluation done at 5 years.

6. An unexplained higher risk of stroke after PCI in NOBLE, which was more than twice after PCI than CABG.

Although opposing findings may have an uncertainty on the optimal revascularization strategy, these trials also demonstrated how much PCI has been improved for LMCA treatment.

\section{Technical Considerations in LM Stenting}

When performing LMCA interventions, the following technical considerations are important.

1. Patient comorbidities: Elderly age, diabetes, renal failure, acute coronary syndrome on presentation, left ventricular dysfunction, concomitant valvular disease, previous cerebrovascular events, and so on. 2. Lesion morphology: Lesion location-Ostial, shaft, or bifurcation, presence of calcification, angulation, smaller LMCA diameter $<3.5 \mathrm{~mm}$, associated multivessel disease, presence or absence of the patent right coronary artery and collaterals to the left system, the dominance of left circumflex. LMCA lesions are classified as simple if SB diameter stenosis is $<70 \%$ and lesion length $<10 \mathrm{~mm}$. A complex LM lesion has SB diameter stenosis $>70 \%$ and lesion length $>10 \mathrm{~mm}$ or if it satisfies two of the following six minor criteria: (1) moderate to severe calcification; (2) multiple lesions; (3) LAD-LCX bifurcation angle > 70 degrees; (4) main vessel reference vessel diameter $<2.5 \mathrm{~mm}$; (5) thrombus-containing lesion; and (6) main vessel lesion length $>25 \mathrm{~mm}$.
3. Use of additional equipment: To optimize and safely accomplish the LMCA intervention, consideration must be given to the use of additional equipment such as intravascular imaging, physiologic assessment, mechanical circulatory support, and ventilatory support.

\section{Role of Coronary Imaging for LM Stenting}

The results from the multicenter LITRO study indicated that LMCA intervention may be safely deferred if the minimal lumen area by IVUS is $>6 \mathrm{~mm} 2$. In this study comprising of 354 patients, LMCA intervention was deferred in 179 of 186 patients and undertaken 152 of 168 patients based on the minimal lumen area cut-off value of $6 \mathrm{~mm} 2$. During a 2-year follow-up, no difference was observed in cardiac death or events [28]. It is important to perform IVUS pull back from LAD and LCX into LMCA to assess the plaque burden at the Ostia of these branches and also to disengage the guide catheter to assess the plaque burden at LM ostium. An MLA $<3.7 \mathrm{~mm} 2$ or plaque burden $>56 \%$ in the LCX ostium is a predictor of the need for a second stent after provisional stenting of the main vessel and LM ostium should be stented if the plaque burden is > $50 \%$ at the ostium [29]. Further IVUS also helps to assess the degree and depth of calcification and guides to decide for debulking strategy such as rotablation. Poststent IVUS run will help to detect stent under expansion and mal apposition Poststent minimal stent area to predict angiographic restenosis. The best IVUS criteria of minimal stent area predicting angiographic restenosis were $5.0 \mathrm{~mm} 2$ for the left circumflex artery ostium, $6.3 \mathrm{~mm} 2$ for the LAD ostium, $7.2 \mathrm{~mm} 2$ for the polygon of confluence, and $8.2 \mathrm{~mm} 2$ for the proximal LMCA above the polygon of confluence (so-called 5-6-7-8 rule of criteria) [30].

Optical coherence tomography (OCT) is the newer imaging modality with higher resolution and faster pull-back speed to assess the intravascular characteristics of the vessel and plaque. OCT is especially useful to identify stents under expansion and malposition with more precision compared to IVUS. Although at present no guideline recommendations are available for OCT-derived LM for intervention [31].

\section{Strategies for LM Stenting}

Ostial and shaft lesions may be easily carried out by appropriately sized stents and optimizing the result with post-dilation using a non-compliant balloon. When treating ostial LM lesions one or two struts should be positioned into the aorta and adequate dilatation should be done without causing dissection of the aorta.

Distal LM lesions may be treated by several approaches:

1. Cross-over strategy: Stent placement across LM into either LAD or LCX and optimizing the LM stent. In the LMCA bifurcation, intimal atherosclerosis is accelerated primarily in the area of low shear stress in the lateral wall close to the LAD and LCx bifurcation. Thus, the carena is frequently free of disease and this can explain the reason why the singlestent strategy can be successfully performed in patients with no or moderate disease by angiography.

2. Provisional stenting strategy: In this strategy, most commonly LMLAD stent is done with a wire protecting the LCX. If there is a significant compromise of LCX or associated with angina or hemodynamic changes, bail-out stenting of LCX may be carried out using T and small protrusion (TAP) or culotte techniques. Before LM stenting, IVUS is helpful to decide in favor of provisional stent strategy. If the IVUS-derived minimal lumen is $>3.7 \mathrm{~mm} 2$ or plaque burden is $<56 \%$ in the LCX ostium, the possibility of an additional stent is minimized [32].

3. Two stent strategy: This strategy may be considered if the LCX is a dominant vessel if LCX ostium has a significant disease, LCX diameter $>2.5 \mathrm{~mm}$, or the angle between LAD and LCX is narrow. Preferred techniques in this situation include T-or TAP-stenting, culotte, and minicrush or double kissing (DK) crush techniques. If the LCX is smaller than LAD with a bifurcation angle $>70 \%$, DK crush is ideal, and if it is $<70 \%$ either culotte or DK crush may be considered. Two stent techniques should be planned well and considered by experienced operators only. 
Final kissing is mandatory in this technique. Two randomized trials have compared the DK crush technique with culotte (DK Crush III) and provisional stenting (DK CRUSH V) and reported significantly low target lesion revascularization and stent thrombosis with the DK crush technique[33,34].

\section{Mechanical Circulatory Support}

IABP is the most commonly available device with easy and expeditious insertion but is associated with low efficacy to augment cardiac output. It may be useful in pre-shock/shock patients, electively, or during emergency crash situations during LM PCI. Impella provides a higher cardiac output and may be considered in high-risk LM PCI or during severe shock. Tandem heart and ECMO are mainly useful for cardiac arrest situations. It is very important to plan the device strategy before the commencement of LM intervention [35].

\section{Conclusions}

Percutaneous intervention with stent implantation for LMCA disease has become a standard procedure in contemporary practice with safety, expedited recovery, and durability. Precise selection of the strategy aided by intracoronary imaging, functional evaluation, and mechanical support when needed has improved the immediate and long-term results in this high-risk intervention. It is however important to have a team approach and operator expertise before embarking on LMCA interventions.

\section{References}

1. Stone P, Goldschlager N. Left main coronary artery disease: review and appraisal. Cardiovasc Med 1979; 4:165-177.

2. Leaman DM, Brower RW, Meester GT, Serruys P, van den Brand M. Coronary artery atherosclerosis: severity of the disease, the severity of angina pectoris and compromised left ventricular function. Circulation 1981; 63(2):285-299.

3. DeMots H, Rösch J, McAnulty JH, Rahimtoola SH. Left main coronary artery disease. Cardiovasc Clin 1977; 8(2):201-211.

4. Taylor HA, Deumite NJ, Chaitman BR, Davis KB, Killip T, Rogers WJ. Asymptomatic left main coronary artery disease in the Coronary Artery Surgery Study (CASS) registry. Circulation 1989; 79(6):1171-1179.

5. DeMots H, Rosch J, McAnulty J. Left main coronary artery disease. Cardiovasc Clin 1977; 8:201-211.

6. Kim SY, Seo JB, Do KH, et al. Coronary artery anomalies: classification and ECG-gated multi-detector row CT findings with angiographic correlation. Radio Graphics. 2006; 26(2):31733.

7. Cheezum MK, Liberthson RR, Shah NR, Villines TC, O'Gara PT, Landzberg MJ, Blankstein R. Anomalous aortic origin of a coronary artery from the inappropriate sinus of Valsalva. J Am Coll Cardiol. 2017; 69:1592-1608.

8. Park SJ, Park DW. Left main stenting: is it a different animal? EuroIntervention. 2010; 6(suppl J): J112-J117.

9. Medrano-Gracia P, Ormiston J, Webster M, Beier S, Young A, Ellis C, Wang C, Smedby Ö, Cowan B. A computational atlas of normal coronary artery anatomy. Euro Intervention. 2016; 12:845-854.

10. PAUL K L, WILLIAM D EDWARDS et al. Coronary arterial anatomy in the bicuspid aortic valve. Necropsy study of 100 hearts. Br Heart Y 1981; 45: 142-147

11. Jean Fajadet and Alaide Chieffo. Current management of left main coronary artery disease. European Heart Journal (2012) $33,36-50$.

12. Chikwe J, Kim M, Goldstone AB, Fallahi A, Athanasiou T. Current diagnosis and management of the left main coronary disease. Eur J Cardio Thorac Surg. 2010; 38(4):420-428.
13. Farinha JB, Kaplan MA, Harris CN, Dunne EF, Carlish RA, Kay JH, Brooks S. Disease of the left main coronary artery. Surgical treatment and long-term follow-up in 267 patients. Am J Cardiol 1978; 42:124-12.

14. Pramod Kumar Kuchulakanti.Left Main PCI-Current Evidence, Techniques, and Triumph. Indian Journal of Clinical Cardiology 1(2) 86-93, 2020.

15. Jakub Sulženko, PiotrPieniazek. The cardiovascular risk of patients with carotid artery stenosis. Cor et VasaVolume 60 issue 1, February 2018, Pages e42-e48.

16. Oviedo C, Maehara A, Mintz GS, et al. Intravascular ultrasound classification of plaque distribution in left main coronary artery bifurcations: where is the plaque really located? Circ Cardiovasc Interv. 2010; 3(2):105-112.

17. Wykrzykowska JJ, Mintz GS, Garcia-Garcia HM, et al. Longitudinal distribution of plaque burden and necrotic corerich plaques in non-culprit lesions of patients presenting with acute coronary syndromes. JACC Cardiovasc Imaging 2012; 5 (3, Suppl): S10-S18.

18. Yusuf S, Zucker D, Peduzzi P, Fisher LD, Takaro T, Kennedy JW, Davis K, Killip T, Passamani E, Norris R. Effect of coronary artery bypass graft surgery on survival: an overview of 10-year results from randomized trials by the Coronary Artery Bypass Graft Surgery Trialists Collaboration. Lancet 1994; 344:1446.

19. Sabik JF, Blackstone EH, Firstenberg M, Lytle BW. A benchmark for evaluating innovative treatment of left main coronary disease. Circulation 2007; 116(Suppl. I): I-232-I-239.

20. Gruntzig A, Transluminal dilatation of coronary-artery stenosis (letter). Lancet. 1978; 1(8058):263.

21. O'Keefe JH Jr, Hartzler GO, Rutherford BD, McConahay DR, Johnson WL, Giorgi LV, Ligon RW. Left main coronary angioplasty: early and late results of 127 acute and elective procedures. Am J Cardiol 1989; 64:144-147.

22. Neumann FJ, Sousa-Uva M, Ohlsson A et al. 2018 ESC/ EACTS Guidelines on myocardial revascularization. Eur Heart J. 2019; 40(2):87-165.

23. Fihn SD, Blankenship JC, Alexander KP, et al. 2014 ACC/AHA/ AATS/PCNA/SCAI/STS focused update of the guideline for the diagnosis and management of patients with stable ischemic heart disease: a report of the American College of Cardiology/ American Heart Association Task Force on Practice Guidelines, and the American Association for Thoracic Surgery, Preventive Cardiovascular Nurses Association, Society for Cardiovascular Angiography and Interventions, and Society of Thoracic Surgeons. J Am Coll Cardiol 2014; 64(18):1929-1949.

24. Morice MC, Serruys PW, Kappetein AP, et al. Five-year outcomes in patients with the left main disease treated with either percutaneous coronary intervention or coronary artery bypass grafting in the Synergy between Percutaneous Coronary Intervention with Taxus and Cardiac Surgery trial. Circulation 2014; 129(23):2388-2394.

25. Stone GW, Sabik JF, Serruys PW, et al; EXCEL Trial Investigators. Everolimus-eluting stents or bypass surgery for left main coronary artery disease. N Engl J Med 2016; 375(23):2223-2235.

26. Mäkikallio T, Holm NR, Lindsay $M$, et al; NOBLE study investigators. Percutaneous coronary angioplasty versus coronary artery bypass grafting in treatment of unprotected left main stenosis (NOBLE): a prospective, randomized, openlabel, non-inferiority trial. Lancet 2016; 388(10061):27432752 . 
27. Waqas Ullah, Yasar Sattar, Irfan Ulla, et al . Percutaneous Intervention or Bypass Graft for Left Main Coronary Artery Disease? A Systematic Review and Meta-Analysis. Hindawi Journal of Interventional Cardiology Volume 2020, Article ID 4081642, 8 pages

28. de la Torre Hernandez JM, Hernández Hernandez F, Alfonso F, et al. Prospective application of pre-defined intravascular ultrasound criteria for assessment of intermediate left main coronary artery lesions results from the multicenter LITRO study. J Am Coll Cardiol. 2011; 58(4):351-358.

29. Park SJ, Ahn JM, Kang SJ. Unprotected left main percutaneous coronary intervention: integrated use of fractional flow reserve and intravascular ultrasound. J Am Heart Assoc. 2012; 1:e004556. DOI: 10.1161/ JAHA.112.004556.

30. Kang SJ, Ahn JM, Song H, Kim WJ, Lee JY, Park DW, Yun SC, Lee SW, Kim YH, Lee CW, Mintz GS, Park SW, Park SJ. Comprehensive intravascular ultrasound assessment of stent area and its impact on restenosis and adverse cardiac events in 403 patients with the unprotected left main disease. Circ Cardiovasc Interv. 2011; 4:562-569.

31. Dato I, Burzotta F, Trani C et al. Optical coherence tomography guidance for the management of angiographically intermediate left main bifurcation lesions: early clinical experience. Int J Cardiol. 2017; 248:108-113.

32. Lassen JF, Burzotta F, Banning AP et al. Percutaneous coronary intervention for the Left main stem and other bifurcation lesions. The 12th consensus document from the European Bifurcation Club. EuroIntervention. 2018; 13(13):1540-1553.

33. Chen SL, Xu B, Han YL, et al. Comparison of double kissing crush versus culotte stenting for unprotected distal left main bifurcation lesions: results from a multicenter, randomized, prospective DKCRUSH-III study. J Am Coll Cardiol 2013; 61(14):1482-1488.

34. Chen SL, Zhang JJ, Han Y, et al. Double Kissing Crush Versus Provisional Stenting for Left Main Distal Bifurcation Lesions: DKCRUSH-V randomized trial. J Am Coll Cardiol 2017; 70(21):2605-2617.

35. Atkinson TM, Ohman EM, O Neil WW, Rab T, Cigarroa JE. A practical approach to mechanical circulatory support in patients undergoing percutaneous coronary intervention: an interventional perspective. JACC Cardiovasc Interv. 2016; 9(9):871-883.
This work is licensed under Creative Commons Attribution 4.0 License

\section{To Submit Your Article Click Here: Submit Manuscript}

DOI:10.31579/2641-0419/209
Ready to submit your research? Choose Auctores and benefit from:

* fast, convenient online submission

* rigorous peer review by experienced research in your field

* rapid publication on acceptance

* authors retain copyrights

* unique DOI for all articles

* immediate, unrestricted online access

At Auctores, research is always in progress.

Learn more www.auctoresonline.org/journals/clinical-cardiology-andcardiovascular-interventions 